\title{
REVESTIMENTOS CERÃMICOS SEMIPOROSOS OBTIDOS COM ADIÇÃO DE FONOLITOS EM MASSAS ARGILOSAS CAULINÍTICAS *
}

\section{Resumo}

\author{
Markssuel Teixeira Marvila ${ }^{1}$ \\ Jonas Alexandre ${ }^{2}$ \\ Afonso Rangel Garcez Azevedo ${ }^{3}$ \\ Euzébio Bernabé Zanelato ${ }^{4}$ \\ Sergio Neves Monteiro \\ Gustavo de Castro Xavier ${ }^{6}$ \\ Greisson Peixoto Rangel ${ }^{7}$
}

Este trabalho tem por objetivo avaliar a possibilidade de obtenção de revestimento cerâmico prensado semiporoso utilizando misturas, por via seca, de argila caolinítica com fonolíto. Foram utilizados traços contendo $20 \%$ e $40 \%$ de incorporação de fonolíto em peso em relação a massa cerâmica em duas granulometrias distintas (fonolíto passado na peneira \#50 e \#200). Para efeito comparativo, avaliou-se uma massa cerâmica industrial proveniente do polo cerâmico de Campos dos Goytacazes e uma massa cerâmica sem incorporação de fonolíto. Foram preparados corpos de prova por prensagem uniaxial calcinados em temperaturas variando entre 1050 a $1200^{\circ} \mathrm{C}$. Nas amostras queimadas, foram realizados ensaios tecnológicos para determinação da retração linear, resistência mecânica (compressão diametral) e absorção de água. Os resultados mostraram que a adição de fonolíto reduziu a absorção de água da argila. Além disso, o incremento do teor de fonolíto e a redução de sua granulometria somente foram eficientes em temperaturas elevadas. Com isso, a incorporação de fonolíto a uma argila caolinítica pode possibilitar a obtenção de revestimentos semiporosos com parâmetros melhorados. Entretanto uma ressalva dever ser feita: há necessidade de incremento da temperatura final de queima em comparação com patamares utilizados por indústrias do polo cerâmico de Campos dos Goytacazes.

Palavras-chave: Argila caolinítica, Fonolíto, Revestimento Cerâmico Semiporoso.

\section{SEMIPOROUS CERAMIC COATINGS OBTAINED WITH ADDITION OF PHONOLITES IN CAULINIQUE ARGYLUS PASTS.}

\begin{abstract}
This work aims to evaluate the possibility of obtaining a semiporous pressed ceramic coating using dry mixtures of kaolinite clay with phonolite. Traces containing $20 \%$ and $40 \%$ of fonolite incorporation by weight in relation to the ceramic mass were used in two distinct granulometries (phonolite passed in the \# 50 and \# 200 sieves). For comparative purposes, an industrial ceramic mass was obtained from the Campos dos Goytacazes ceramic pole and a ceramic mass without incorporation of fonolíto. Uniaxial pressing specimens calcined at temperatures ranging from 1050 to $1200^{\circ} \mathrm{C}$ were prepared. In the burned samples, technological tests were carried out to determine linear retraction, mechanical strength (diametrical compression) and water absorption. The results showed that the addition of phonolite reduced the water absorption of the clay. In addition, the increase of the phonolite content and the reduction of its granulometry were only efficient at high temperatures. Thus, the incorporation of phonolite into a kaolinitic clay can make it possible to obtain semiporous coatings with improved parameters. However, a caveat must be made: there is a need to increase the final firing temperature in comparison to the levels used by the Campos dos Goytacazes.
\end{abstract}

Keywords: Clay kaolinite, Fonolite, Semi Porous Ceramic Flooring. 
1 Engenheiro Civil, mestrando em Estruturas, LECIV, Universidade Estadual do Norte Fluminense Darcy Ribeiro, Campos dos Goytacazes, RJ, Brasil.

2 Engenheiro Civil, doutor em Estruturas, LECIV, Universidade Estadual do Norte Fluminense Darcy Ribeiro, Campos dos Goytacazes, RJ, Brasil.

3 Engenheiro Civil, doutorando em Estruturas, LECIV, Universidade Estadual do Norte Fluminense Darcy Ribeiro, Campos dos Goytacazes, RJ, Brasil.

4 Engenheiro Civil, doutorando em Estruturas, LECIV, Universidade Estadual do Norte Fluminense Darcy Ribeiro, Campos dos Goytacazes, RJ, Brasil.

5 Engenheiro Metalúrgico, PhD em Engenharia e Ciência dos Materiais, IME, Instituto Militar de Engenharia, Rio de Janeiro, RJ, Brasil.

6 Engenheiro Civil, doutor em Ciências de Engenharia, LECIV, Universidade Estadual do Norte Fluminense Darcy Ribeiro, Campos dos Goytacazes, RJ, Brasil.

7 Engenheiro civil, mestrando em Estruturas, LECIV, Universidade Estadual do Norte Fluminense Darcy Ribeiro, Campos dos Goytacazes, RJ, Brasil. 


\section{INTRODUÇÃO}

A utilização de argilas caoliníticas como únicos componentes na massa para obtenção de revestimentos cerâmicos é inapropriada, principalmente por causa do comportamento refratário que esse tipo de material tem. Diversos trabalhos estudando as argilas da região de Campos dos Goytacazes chegaram à conclusão de que, a argila presente nessa região caracterizada por ser caoliníticas não é ideal para ser usada em revestimento cerâmico semiporosos. [1] [2]

Contrapondo a isso, as argilas fundentes ilíticas são utilizadas mundialmente para fabricação de artefatos de cerâmica vermelha, sendo utilizados como único componente, ou até mesmo em associação com outros materiais [3] [4] [5]. Assim espera-se que o uso de massa cerâmica típica da região de Campos, e, portanto caoliníticas, associada com fonolíto possa proporcionar a obtenção de peças de cerâmica com boas propriedades tecnológicas.

Desta forma o objetivo desse trabalho é verificar a possibilidade de obtenção de revestimento cerâmico semiporoso por via seca através da mistura de argila caoliníticas da região de Campos dos Goytacazes com fonolíto agindo como material fundente.

\section{MATERIAIS E MÉTODOS}

Para estudar a possibilidade da adição de fonolíto em massa cerâmica caoliníticas os seguintes materiais foram utilizados: argila plástica caoliníticas proveniente do município de Campos dos Goytacazes região norte do estado do Rio de Janeiro, fonolíto proveniente do polo cerâmico de Curimbaba, estado de Minas Gerais.

Os traços estudados foram os seguintes: um traço de referência obtido das cerâmicas da região de Campos que fabricam revestimento semiporosos e nomeado como massa industrial, uma mistura contendo em sua composição $100 \%$ de argila caoliníticas também utilizada para referência, e quatro traços contendo em sua composição $20 \%$ e $40 \%$ de incorporação de fonolíto com duas granulometrias diferentes, passadas nas peneiras $\# 50$ e \#200. A tabela 1 resume os traços empregados neste estudo.

Com exceção da massa industrial, as demais amostras recebidas foram beneficiadas, sendo triturada a seco em moinho de bolas e posteriormente peneirada, parte do fonolíto em peneira \#50 e parte em peneira \#200, e a argila caoliníticas em peneira \#40. As misturas foram então realizadas e homogeneizadas a seco em moinho de bolas por 1 hora.'

Tabela 1. Traços estudados com suas respectivas porcentagens

\begin{tabular}{|c|c|c|c|c|c|c|}
\hline \multirow{2}{*}{ Material } & \multicolumn{7}{|c|}{ Traço Nomeado } \\
\cline { 2 - 7 } & MI & AC & A20F\#50 & A40F\#50 & A20F\#200 & A40F\#200 \\
\hline Massa Industrial & 100 & 0 & 0 & 0 & 0 & 0 \\
\hline Argila Caolinítica & 0 & 100 & 80 & 60 & 80 & 60 \\
\hline Fonolito & 0 & 0 & 20 & 40 & 20 & 40 \\
\hline
\end{tabular}

Para realização dos ensaios tecnológicos foram preparados corpos-de-prova cilíndricos $(\varphi=31,5 \mathrm{~mm}$, com $8 \mathrm{~mm}$ de espessura) por prensagem uniaxial a $25 \mathrm{MPa}$ mantendo-se $8 \%$ de umidade. Os corpos-de-prova foram secos em estufa a $110^{\circ} \mathrm{C}$ 
por 24 horas. A queima foi realizada em forno de laboratório nas temperaturas de 1050 a $1200^{\circ} \mathrm{C}$, com intervalos de $50^{\circ} \mathrm{C}$. A taxa de aquecimento empregada foi de $10^{\circ} \mathrm{C} / \mathrm{min}$, com 6 min de permanência na temperatura de patamar. O resfriamento foi realizado desligando-se o forno e aguardando que a temperatura caísse.

Após queima, as amostras foram submetidas aos seguintes ensaios tecnológicos: retração linear, absorção de água e resistência mecânica, avaliada pela determinação da compressão diametral.

A retração linear foi obtida através da determinação do comprimento das amostras antes e após queima utilizando um paquímetro digital. A absorção de água foi obtida através do método da fervura, determinando o peso das amostras secas e saturadas com água. E por fim a tensão de ruptura à flexão foi determinada em máquina universal de ensaios com uma velocidade de aplicação de carga de $0,5 \mathrm{~mm} / \mathrm{min}$. A resistência a compressão diametral é obtida empregando a seguinte expressão:

Onde:

$$
\sigma=\frac{2 P}{\pi \emptyset e}
$$

$\mathrm{P}=$ carga de ruptura em $\mathrm{N}$;

$\Phi=$ diâmetro do corpo de prova em $\mathrm{mm}$;

$\mathrm{e}=$ espessura do corpo de prova em $\mathrm{mm}$;

\section{RESULTADOS E DISCUSSÃO}

A tabela 2 apresentada a análise química das matérias-primas estudadas. Destacase que a argila caolinita apresenta elevados teores de alumina e baixo percentual de sílica, além de apresentar baixas quantidades de óxidos fundentes e elevada perda ao fogo. Comparada com a argila caolinítica, a massa industrial apresenta baixo teor de alumina e elevado teor de sílica, apresentando também elevados teores de óxidos fundentes $\left(\mathrm{K}_{2} \mathrm{O}+\mathrm{Na}_{2} \mathrm{O}\right)$ e baixo valor de perda ao fogo. Por último o fonolíto apresenta elevado percentual fundente destacado pelo alto teor de óxidos fundentes que existe em sua composição.

Tabela 2. Análise Química das Matérias-Primas.

\begin{tabular}{|c|c|c|c|}
\hline Óxidos & Argila Caulínitica & Massa Industrial & Fonolito \\
\hline $\mathrm{SiO} 2$ & 50,12 & 66,42 & 54,23 \\
\hline $\mathrm{Al} 2 \mathrm{O} 3$ & 25,18 & 15,7 & 21,78 \\
\hline $\mathrm{Fe} 2 \mathrm{O} 3$ & 8,79 & 5,87 & 3,45 \\
\hline $\mathrm{TiO} 2$ & 1,23 & 0,64 & 0,61 \\
\hline $\mathrm{CaO}$ & 0,37 & 0,38 & 1,43 \\
\hline $\mathrm{MgO}$ & 1,04 & 1,76 & 0 \\
\hline $\mathrm{Na2O}$ & 0,48 & 1,03 & 7,12 \\
\hline $\mathrm{K} 2 \mathrm{O}$ & 1,87 & 3,41 & 8,26 \\
\hline $\mathrm{PF}$ & 10,3 & 4,52 & 2,45 \\
\hline
\end{tabular}

A Figura 1 apresenta as curvas de distribuição de tamanho de partícula das matérias-primas estudadas. Observa-se que a argila caoliníticas apresenta uma granulometria um pouco mais fina que à massa industrial. Isso provavelmente ocorreu porque a massa $\mathrm{Ml}$ apresentada provém de moagem industrial enquanto a argila caolinítica estuda foi tratada e moída em laboratório. O tamanho médio de partícula da argila caolinítica e da massa cerâmica industrial é de respectivamente 
6,51 e 10,63 $\mu \mathrm{m}$. Já o fonolito apresenta-se com duas granulometrias distintas. 0 fonolito mais fino foi triturado em moinho de bolas até passagem em malha de \# 200 $(75 \mu \mathrm{m})$ e o mais grosseiro foi passado na peneira \# 50. O tamanho médio de partícula do fonolito F \# 50 e F \# 200 é de 17,0 e 29,8 $\mu \mathrm{m}$, respectivamente
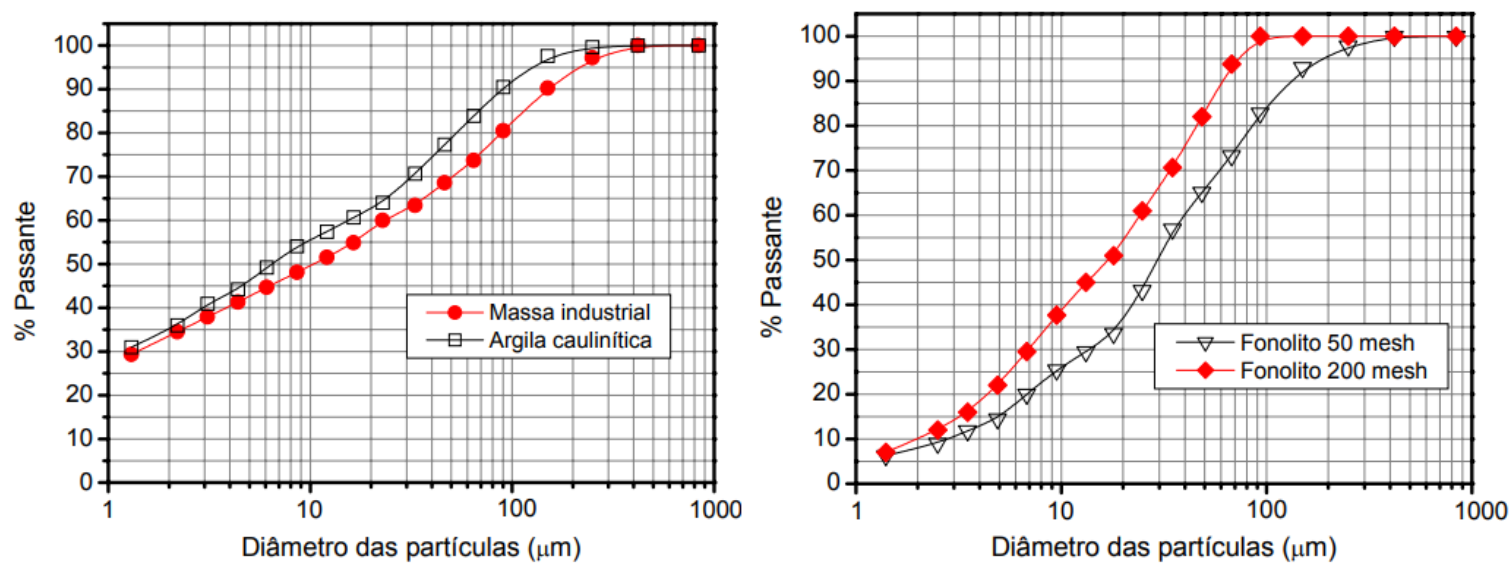

Figura 1. Distribuição Granulométrica das matérias-primas estudadas

As Figuras 2 e 3 apresentam o comportamento da absorção de água e da retração linear dos traços estudados em função da temperatura de queima, respectivamente. Observando a Fig. 3, é fácil comparar o comportamento da argila caolinítica com a massa cerâmica industrial de revestimento semiporoso. A argila caolinítica apresenta valores muito superiores de absorção de água em todas as temperaturas avaliadas. Este comportamento é bem conhecido na literatura sendo associado à maior fundência de argilas ilíticas em comparação com argilas caoliníticas [1] [2] [4]. A incorporação de fonolito, material considerado fundente devido ao elevado teor de óxidos alcalinos, possibilitou uma redução dos valores de absorção de água em comparação com a argila pura. $O$ fonolito foi incorporado à argila caolinítica em duas granulometrias diferentes, < \# 50 e < \# 200, e em duas proporções, 20 e 40\% em peso. Nas temperaturas iniciais avaliadas, o menor teor de fonolito incorporado, $20 \%$, foi mais eficiente na redução da absorção de água em comparação com maiores quantidades, 40\%. Apesar do incremento de óxidos alcalinos com 0 aumento de fonolito incorporado, observado na Tabela 2, o aumento da absorção de água pode ser atribuído principalmente ao menor grau de compactação obtido. Observa-se também que a redução da granulometria do fonolito só foi eficiente em temperaturas acima de $1150^{\circ} \mathrm{C}$. Apesar da redução da absorção de água com incorporação de fonolito, os valores obtidos são superiores à massa industrial. Isto pode ser atribuído à granulometria extremante pequena da ilita em comparação com o fonolito o que contribui para uma reatividade muito mais eficiente durante as reações que ocorrem na queima. Os menores valores de absorção de água foram obtidos obviamente na temperatura de queima mais elevada, ou seja, de $1200^{\circ} \mathrm{C}$ para a massa industrial seguido do traço AC40F\#200, evidenciando que a adição de $40 \%$ de fonolíto com granulometria mais fina é de fato eficiente no controle de absorção de água. 


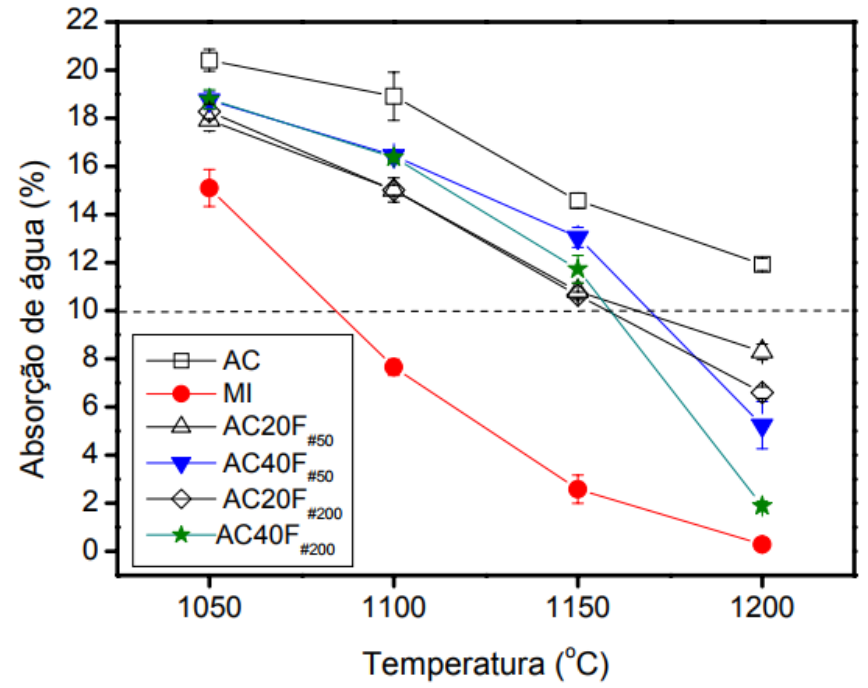

Figura 2. Absorção de água por temperatura para os traços estudados.

De acordo com a Fig. 3 observa-se que, excetuando-se a massa industrial na temperatura de $1200^{\circ} \mathrm{C}$, o incremento da temperatura de queima acarreta um aumento da retração linear. Este comportamento é atribuído ao fechamento da porosidade que possibilita uma densificação das peças acompanhada de retração. Diferentemente da absorção de água, o comportamento da retração linear da massa industrial está mais próximo das demais composições. Este comportamento é atribuído principalmente ao baixo valor de perda ao fogo que está relacionado com um incremento da retração de queima. Isto significa que, apesar da maior fundência da massa industrial, sua retração não é tão significativa em função de sua baixa perda de massa durante a queima.

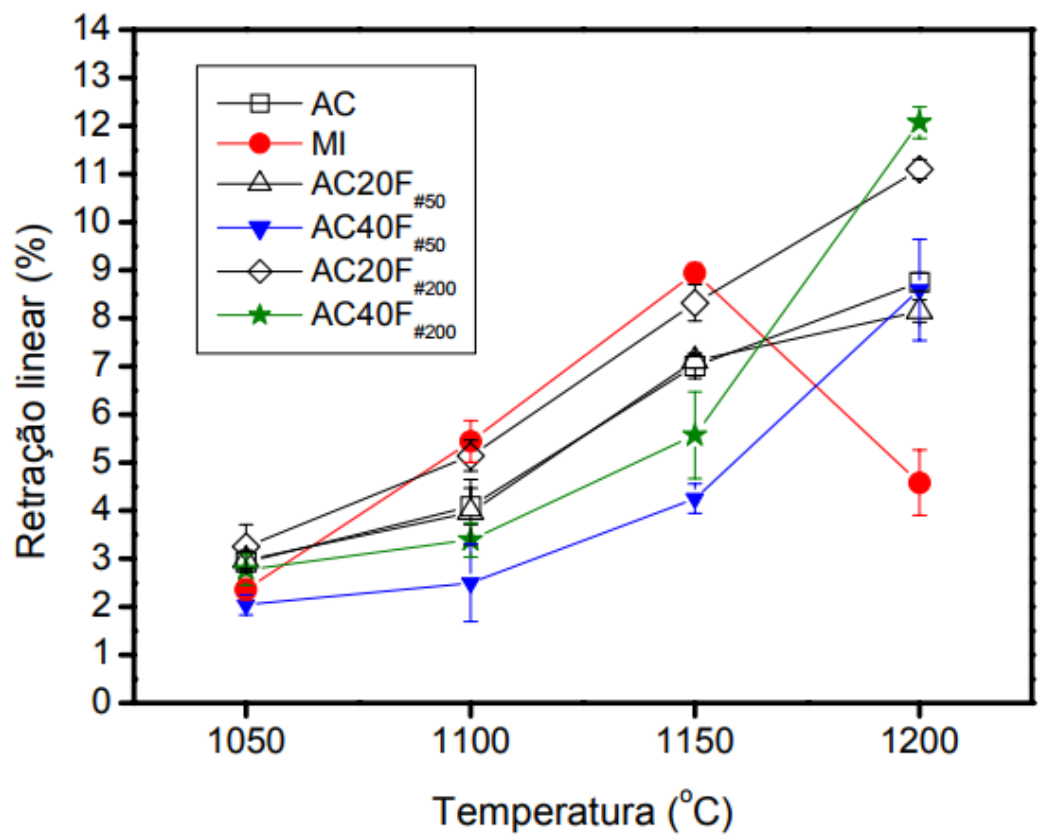

Figura 3. Retração linear por temperatura para os traços estudados.

A Figura 4 apresenta a resistência mecânica, avaliada por ensaio de compressão diametral, dos traços estudados em função da temperatura de queima. Observa-se que em função da menor porosidade, a massa industrial apresentou maiores valores 
de resistência mecânica nas temperaturas de 1100 e $1150^{\circ} \mathrm{C}$. A $1050^{\circ} \mathrm{C}$, apesar de possuir menor porosidade, a massa industrial apresentou resistência mecânica similar à argila caulinítica. Isto pode ser atribuído à maior presença de quartzo de granulometria grosseira, observado na tabela 2, que contribui para a redução da resistência mecânica [2] [5]. As composições com $40 \%$ de fonolito apresentaram menores valores de resistência mecânica até $1150^{\circ} \mathrm{C}$. Assim destaca-se que a adição de fonolíto foi mais efetivo para o parâmetro resistência mecânica utilizando a temperatura de queima de $1200^{\circ} \mathrm{C}$. optou-se por não comparar com os valores estipulados pela norma, já que a norma toma como base a resistência á flexão, e nesse estudo foi analisado a resistência á compressão.

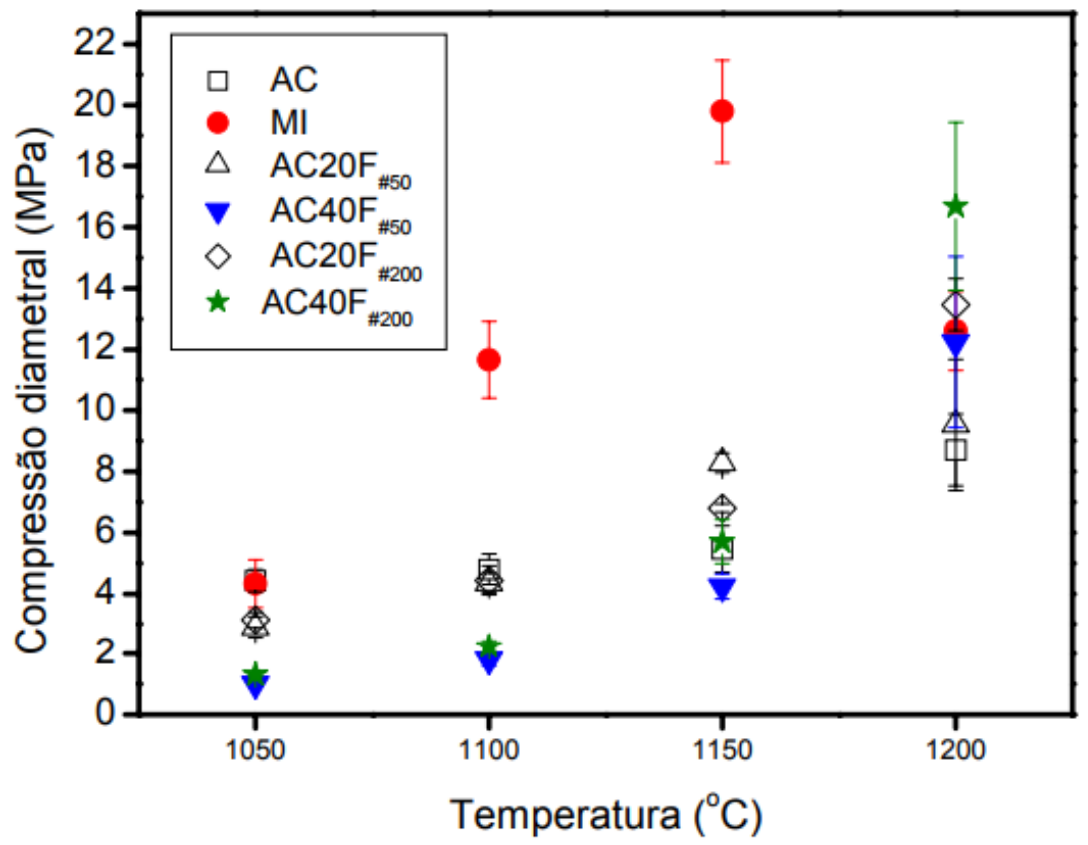

Figura 4. Resistência Mecânica por temperatura para os traços estudados.

\section{CONCLUSÃO}

Tomando como base os resultados obtidos é possível concluir que:

- A incorporação de fonolíto em $20 \%$ e $40 \%$ do peso em argila caolinítica contribui significativamente para as propriedades de queima.

- Entretanto, em comparação com uma típica massa industrial de revestimento semiporoso, as composições argila caolinítica/fonolito ainda apresentam algumas características químicas significativamente diferentes como uma menor relação $\mathrm{SiO}_{2} / \mathrm{Al}_{2} \mathrm{O}_{3}$ e maior PF. Esta última característica pode ocasionar o aparecimento de defeitos em uma queima industrial.

- Durante a queima, as composições com fonolíto só alcançam o patamar máximo de absorção de água para revestimento semiporoso em temperaturas $80^{\circ} \mathrm{C}$ acima da massa industrial, e, além disso, em temperaturas de queima tipicamente utilizadas no Brasil (1080 a $\left.1130^{\circ} \mathrm{C}\right)$, a massa industrial apresentou resistência mecânica muito acima dos traços que possuíam adição de fonolíto.

- Por fim, não se recomenda aumentar a quantidade de fonolito incorporado à argila caoliníticas já que vai prejudicar a plasticidade e consequentemente a compactação das massas. 


\section{REFERÊNCIAS}

1 Vieira, C. M. F.; Monteiro, S. N.; Duailibi Filho, J. Formulação de massa de revestimento cerâmico com argilas plásticas de Campos dos Goytacazes (RJ) e taguá (SP).Cerâmica Industrial, v. 6, p. 43-47, 2001.

2 Vieira, C. M. F.; Soares, T. M.; Monteiro, S. N.; Revestimento cerâmico com granito e argila caulinítica. Cerâmica, v.54, p. 122-127. 2004.

3 Dos Santos, C. V.; Chagas, A. A. P.; Castral Jr. V. Estudo da influência da proporção dos argilominerais ilita/caulinita nas propriedades físicas de argilas da região de Santa Gertrudes (SP). In: Congresso Brasileiro de Cerâmica. Anais 43ํㅡ, Florianópolis: Brasil, 1999.

4 Riella, H.G., Franjhdlich, E.U., Durazzo, M. Caracterização e Utilizaçaõ de Fundesntes em Massa Cerâmica. Cerâmica Industrial, vol. 7, pgs 33- 36, 2002.

5 Andrade, P M, et al. Efeito da adição de fonolito na sinterização de argila caulinítica. Revista Cerâmica, vol 51, pgs 361-370. 2005. 